\title{
Engaging for Results in Civil Service Reforms: Early Lessons from a Problem-Driven Engagement in Sierra Leone
}

\author{
Benjamin Roseth $^{1} \&$ Vivek Srivastava ${ }^{2}$ \\ ${ }^{1}$ Inter-American Development Bank, Washington DC, USA \\ ${ }^{2}$ Governance Global Practice, the World Bank Group, Washington DC, USA \\ Correspondence: Benjamin Roseth, Young Professional at the Inter-American Development Bank, Washington, DC, \\ USA. E-mail: broseth@iadb.org
}

Received: March 20, 2015

Accepted: May 5, 2015

Online Published: May 11, 2015

doi:10.5430/jms.v6n2p53

URL: http://dx.doi.org/10.5430/jms.v6n2p53

\begin{abstract}
Two related propositions have been central in the recent debates on public sector reforms. The first of these is that the appropriate measure of institutional strength is the ability of public sector management systems to deliver results ("functionality") rather than what these institutions look like ("form"). This is a central idea in the World Bank's Public Sector Management (PSM) Approach (World Bank 2012 a). Second, and consistent with this, is the recognition that the process of engagement matters in the sense that how problems, solutions and reform approaches are identified matters at least as much as what the solution is. This suggests that development institutions should focus on bringing a broad range of stakeholders together and facilitate a process of collective problem and solution identification. Other recent contributions to the literature (Andrews et al 2012) describe a "Problem-Driven Iterative Adaptation" (PDIA) approach as a means of putting this idea into practice. While both of these propositions have considerable intellectual and intuitive appeal, they are based on an inductive logic and neither is currently backed with a robust body of evidence. This paper contributes to this literature by documenting the experience of a civil service reform project - the World Bank-financed Sierra Leone Pay and Performance Project - the objective of which is to improve the performance of the civil service in Sierra Leone by targeting a narrowly defined set of critical reforms. The engagement process and project design draw on key elements of the guidance offered by the World Bank's PSM Approach and PDIA The paper concludes that intensive, client-led engagement together with a use of a financing instrument that focuses on results provides a promising way forward on a difficult reform agenda.
\end{abstract}

Keywords: civil service reform, Sierra Leone, fragile states, results-based financing, PDIA

\section{Introduction}

Two propositions have been central in the recent debates on public sector reforms in developing countries. The first of these is that the effectiveness of the public service and public sector management institutions and systems is not determined by what these look like (their "form") and whether they conform to notions of "best practice" but should be based on what they are able to deliver (their "functionality"). This is a central idea in the World Bank's Public Sector Management (PSM) Approach 2011 - 2020 (World Bank 2012), which, based on the lessons learned over the past several decades of the Bank's support to public management reforms in a wide variety of development contexts, proposes a problem-solving approach based on relative agnosticism about what might work, systematic diagnostics of the binding constraints to well identified functional problems, agility in implementation and a systematic use of available evidence. The emphasis in the World Bank's PSM Approach is on being relatively agnostic about what is likely to works in a particular context and on finding local solutions to functional problems rather than on importing readymade (form-based) "solutions". (Note 1) Second, and consistent with this, is the recognition that the process of engagement matters in the sense that how problems, solutions and reform approaches are identified matters at least as much as what the solution is. Andrews (2008) argues that "the basis of intervention is to create space in which the developing entity can identify, define and solve its own problems". This line of thinking (see also Andrews et al 2012, World Bank 2012, Blum et al 2012) suggests that development institutions should focus on bringing a broad range of stakeholders together and facilitate a process of collective problem and solution identification. Andrews et al (2012) further develop this idea to describe a "Problem-Driven Iterative Adaptation" (PDIA) approach as a means of putting this into practice. "Iterative adaptation" also requires flexibility during implementation and, in effect, does not distinguish between project preparation and implementation. 
With respect to available instruments that development institutions can use to support such reforms, there is an emerging view that results-based financing may be a relatively more effective means of achieving successful reform outcomes as opposed to traditional instruments that finance - and thus focus on - inputs (World Bank 2012). (Note 2) We suggest in this paper that the focus on results provides incentives for better coordination between different agencies within government as well as flexibility in the identification of reform approaches during the project design stage. On the other hand, the instruments currently available provide less flexibility during implementation.

The literature on "good enough" governance and "best fit" solutions stops short of providing specific answers to what will work where precisely because these appropriate solutions are likely to be context-specific and idiosyncratic. (Note 3) Recent work by Andrews et al (2012) provides more specific guidance on the process of engagement for state-building efforts in diverse, often low-capacity environments. The Problem-Driven Iterative Adaptation (PDIA) approach states that efforts to build state capacity should: (i) aim to solve particular problems in well-understood unique local contexts, (ii) facilitate an "authorizing environment" in which actors are permitted to experiment throughout the reform process, (iii) implement rapid feedback loops for ongoing incorporation of lessons learned, and (iv) involve a broad group of stakeholders to ensure the relevance and legitimacy of reform efforts. This paper documents the project preparation and early implementation experience from a World Bank-supported civil service reform project - the Sierra Leone Pay and Performance Project (P\&PP). The objective of the project is to improve the performance of the civil service in Sierra Leone, which still suffers from the legacy of the long civil war, by targeting a narrowly defined set of critical reforms. (Note 4) The P\&PP is a US \$17.0 million IDA-financed civil service reform project with targeted interventions in three select reform areas: pay reform, recruitment and staffing, and performance management. (Note 5) The project has a US \$ 15.0 million component that disburses against the achievement of "disbursement-linked-indicators" ("DLIs") which mark important milestones and results along reform paths identified by the government team in each of the three reform areas. A US \$2.0 million technical assistant component supports the achievement of these indicators through the provision of specialized consulting services and urgently needed physical inputs. Annex 1 provides a detailed description of project components, sub-components and implementation arrangements, and Annex 2 presents the disbursement-linked indicators. The project was approved by the World Bank's board on May 31, 2012 and became effective on October 23, 2012 and is currently under implementation.

The paper documents how a relatively agnostic approach to the choice of reform paths and a PDIA-type process of engagement during the design stage, supported by a results-based lending instrument, helped to create a more promising environment for reforms on which little progress had been made over the past several years. (Note 6) While it is too early to conclude how the reforms will eventually unfold, there is credible evidence that an intensive and sustained engagement process focused on the joint identification of problems and solutions and the use of a results-based financing instrument has fostered better coordination among formerly fragmented actors in government by improving inter-agency trust and providing incentives for joined-up working. The flexibility at the design stage has allowed solutions to emerge that are likely to be more politically and technically feasible than with traditional approaches. (Note 7) We argue that other approaches, such as a traditional input-based approach, are less likely to foster the required degree of coordination among implementing agencies and that "local" identification of reforms paths and results is more likely to "work with the grain" and allow the emergence of feasible reform paths. (Note 8) Figure 1 displays the operating space for development organizations, highlighting the tension between technical certainty and flexibility in project design, and the choice between results-based and input-based instruments.

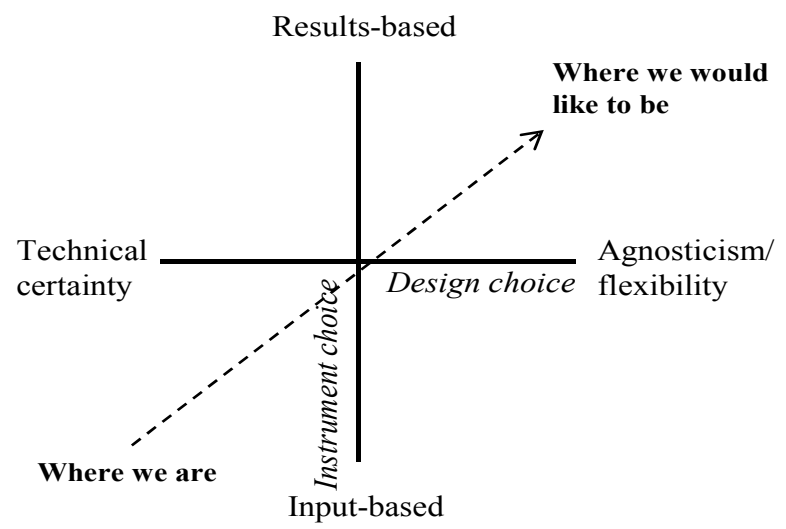

Figure 1. Operating space for development organizations (Note 9) 
While both the PDIA approach and the Bank's Public Sector Management Approach have considerable intuitive appeal, both lack real world examples. This paper contributes to this gap by presenting an example of a project preparation (and early implementation) experience that applies the guidance on the engagement process complemented by the use of a results-based financing instrument. The case presented in this paper has several key features of the PDIA and PSM approaches and provides evidence that this offers a more promising way forward than previous efforts of reform in Sierra Leone. The paper further argues that a results-based lending instrument is a very effective complement to the PDIA approach as it provides incentives for different actors in government to collaborate which is critical for the reform effort to succeed. The paper also contributes empirically to the broader theoretical debate regarding "what works" in public sector management reforms supported by international donors.

The rest the paper is organized in four sections. Section II sets the context by providing a summary of the two broader debates to which the Sierra Leone experience relates - the emphasis on the process of engagement for solving adaptive problems and the value and utility of results-based lending for supporting institutional reforms. Section III provides a brief overview of the civil service reform challenges in Sierra Leone including a description of the fragmentation within government. Section IV documents examples of how a problem solving process and results-based lending helped to build trust and commitment to reform across government in Sierra Leone. Section V concludes by summarizing key lessons learnt from the Sierra Leone experience.

\section{The Context: Emphasis on Problem-Solving Processes and Results-Based Financing}

\subsection{Problem-Solving Processes}

Over the last decade, development practitioners and academics have more explicitly recognized the fallacy of trying to solve adaptive problems through the implementation of hard-wired technical solutions. Current thinking emphasizes the importance of starting with the question "what is the problem?" rather than with a predetermined solution. Traditional approaches that take the "solution" as the starting point are typically based on solutions in which form (what institutions look like) is emphasized over function (how institutions perform). This problem-solving requires starting with ex-ante agnosticism regarding what is likely to work and the involvement of a diverse set of stakeholders, including those with technical, financial and political influence (World Bank 2012). Andrews (2008) argues that a key role that multilaterals such as the World Bank can play in the reform process is that of a "connector". Rather than solely a source of financial support or technical advice, the "connector" has the responsibility for "bridging relational boundaries and bringing people together" (Andrews 2008: 3) to create a space in which reform actors can collectively identify, define and find solutions to their own problems, and in so doing develop ownership of the proposed reforms. Similarly, Booth (2012) argues that "governance challenges ... are ... fundamentally about people finding ways to act collectively in their own best interests" thus highlighting the importance of external actors such as the Bank in supporting the common ground to emerge. Andrews et al (2012) further argue that is necessary to assure broad engagement because change is a product of the interactions among the different actors - as they all occupy essential roles in the reform effort - and cannot be achieved through isolated individual actions. In addition to an inclusive problem-driven approach, both the PDIA framework and PSM Approach emphasize the importance of experimentation. Even if the identified solutions may have merit, they need to pass through a maturation process during which they adapt to local idiosyncrasies, earn political acceptance, and are buttressed with ground-level practical work plans and implementation capacity. Interventions are more likely to be successful when taken in incremental steps during which reform actors observe the impacts of their efforts, uncover contextual constraints and, importantly, learn about what works and what does not. This differs markedly from traditional monitoring and evaluation schemes in which "lessons learned" are only revealed at the end of a project or through the separation of treatment and control groups in randomized control trials.

\subsection{Results-Based Financing}

The past several years have witnessed an evolution of the instruments by which development organizations provide their financial assistance. Traditionally World Bank (other donors have similar instruments) financing has been delivered either through Investment Project Financing (IPF) (Note 10) operations that finance specific inputs or through Development Policy Financing (DPFs) (Note 11) ("Budget Support") which directly finances a government's budget on the achievement of policy reforms referred to as "prior actions". The achievement of a further set of related reforms "triggers" the disbursement of the next tranche.

Previous experience has shown that the IPF instrument is not ideal for financing institutional change and reforms. The design of an IPF requires that all the inputs required for achieving the intended outputs and outcomes are identified at the design stage. The assumption is that the procurement and appropriate use of these inputs would lead to the achievement of intended results. While such an approach is clearly suitable for a road construction project 
where the input mix is quite well known, it is now widely accepted that a much more flexible approach is required for implementing reforms and achieving institutional change. Furthermore, IPF operations do not offer implementing governments flexibility in the use of resources as all resources are tied to specific inputs. While DPF operations are appropriate for supporting policy reforms, they are not well suited or supporting changes in how government actors actually behave and how systems perform. This is largely due to the nature of "prior actions" and "triggers", which are typically at the de jure/policy level - so-called "stroke of the pen" reforms - and do not always involve concrete de facto actions necessary to affect real institutional change. (Note 12)

The World Bank's relatively new results-based lending instrument (Program for Results -PforR) has its roots in IPF projects that financed "eligible expenditures" incurred by governments and disbursed against the ahcivement of disbursement conditions referred to as Disbursement Linked Indicators (DLIs). The PforR instrument is designed to finance a well-defined government "program" with disbursements based on the achievement of the DLIs (Note 13). Since it does not finance inputs, it provides recipient governments relative flexibility in the use of the financial support within the scope of its "program". It is less transactions-intensive and intrusive as, once a recipient's financial management and procurement systems have been assessed, the recipient does not have to refer back to the financing agency for "no objections" and clearances for each transaction. The use of this instrument has the additional benefit of strengthening a client country's public management systems by working through them rather than around them. (Note 14)

For certain reasons that do not have a bearing on the main findings reported in the paper, the Sierra Leone project does not use the PforR instrument; it uses the IPF instrument, finances eligible expenditures and has disbursement conditions in the form of DLIs and includes a technical assistance (TA) component. For the purposes of this paper, the difference between the two approaches is not material.

The present example confirms that an instrument that disburses against the achievement of results can be used effectively for public sector/institutional reform programs and has an advantage over the traditional IPF and DPF instruments provided that there is an agreement on the results to be achieved and on key milestones along the reform path. Further, the focus on results (rather than inputs) and through the careful design of indicators, the instrument has the potential to align incentives, promote coordination and allow for the emergence of politically feasible reform solutions (Srivastava and Larizza 2013). As discussed in Section IV, neither the IPF nor the DPF instruments would have generated similar synergy. However, ven this instrument does not as provide the kind of flexibility during implementation as envisaged in the PDIA.

\section{The Challenge: Improving Civil Service Performance in Sierra Leone}

The performance of the civil service in Sierra Leone is hampered by weak and underperforming human capital as a result of (i) extremely low levels of remuneration that are inadequate for attracting and retaining staff; (ii) patronage-based appointments, promotions and remuneration levels; and (iii) the virtual absence of intrinsic or extrinsic incentives for performance. Possibly as a result of these factors, there are very few staff at the middle and technical levels. Improvements along these dimensions are necessary - though possibly not sufficient - for achieving service delivery improvements. Previous attempts at reform have been impeded by institutional fragmentation compounded by persisting mistrust, resulting in dysfunctional inter-agency collaboration.

\subsection{Weak Human Capital at the Middle and Upper Levels (Note 15)}

Over the years during and after the civil war (which ended in 2002) the public sector in Sierra Leone suffered progressive depletion of skilled manpower in the middle level cadre of professional and technical staff. In Sierra Leone today, over $87 \%$ of the personnel are in the lowest ("blue collar") grades 1-5 (out of 14 grades). Top management grades represent only slightly over $1 \%$ of civil service employment. Professional and technical staff constitutes only about $11 \%$ of the total civil service workforce. (Note 16) This is low by any standard: comparable numbers for professional and technical staff in Gambia (in 2007) were $26 \%$ and $14.3 \%$ in Sudan (in 2004). (Note 17)

Low remuneration appears to be one of the major reasons why Sierra Leone's civil service has not been able to attract and retain suitably qualified professional and technical staff. IEvidence that low remuneration is a key constraint to attracting qualified staff is provided by the fact (i) that entry level personnel recently recruited for certain technical positions had to be paid more than $400 \%$ above regular civil service salaries to accept the appointments and (ii) the plethora of "coping" arrangements that circumvent the low public pay scale (World Bank 2012b, pp. 2). 
The quality of staff in the middle and upper grades is also low. As the civil service atrophied during the civil war, it was generally the most qualified and competent people with marketable skills who left. With some exceptions, the civil servants remaining are those who lack the skills and competencies to find jobs overseas or in the private sector.

A third problem is that Sierra Leone's civil service is demoralized. Unfair pay is an important demotivating factor, as many civil servants are concerned about how they are remunerated in relation to others. (Note 18) The government has not been successful in introducing a pay structure in which relativities are based on the relative worth of the job. Instead, ad hoc pay adjustments for a select few have created significant anomalies and distortions which are resented by the majority of civil servants. (Note 19) This has undermined esprit de corps within the service, which has had an adverse effect on professional cooperation both within and between functions and departments. The vested interests established in the process have made reforms harder to implement.

\subsection{Fragmentation (Note 20)}

While the responsibility for public service reform is fragmented in many countries (by its very nature), in Sierra Leone this fragmentation is greater and, in practice, exacerbates the collective action problem in a government that is characterized by weak coordination and poor information sharing (see Figure 1). Coordination between a large number of offices, ministries and agencies is required for implementing these reforms. These include, at a minimum, the Secretary to the President, the Cabinet Secretary (Head of the Civil Service), the Public Service Commission (PSC), the Human Resources Management Office (HRMO) and the Strategy and Policy Unit in the office of the President. The Ministry of Finance and Economic Development (MoFED) has a key interest in the fiscal impact of pay reforms and is responsible for providing the funding necessary for the reforms. The Public Sector Reform Unit (PSRU), located in the Presidency, is responsible for coordinating and supporting public sector reforms but has no executive authority or implementation responsibilities. Given this web of interlocking and overlapping responsibilities, reforms of the public sector always require complex inter-agency action. In Sierra Leone the challenges are exacerbated by poor communications and mistrust and by the fact that there is no minister responsible for this as the President is the Minister for Public Services.

\subsection{Mistrust/Poor Coordination}

In addition to the complex distribution of responsibilities and multiple reporting lines, the relationship between the MoFED and the various ministries, departments and agencies (MDAs) - including those directly responsible for civil service reform - has historically been characterized by mistrust. The MoFED often views budget submissions from MDAs as unreasonable "laundry lists" of requests rather than prioritized proposals to meet strategic needs. The MDAs, in turn, view the the MoFED's apparently resource allocation decisions as arbitrary and high handed and which they feel leaves them without sufficient resources to fulfill their basic mandates.

To push urgently-needed programs, the government, with donor support, has often implemented reforms that have, in the process, undermined the central agencies formally responsible for the process. For example, the World Bank, through its Institutional Reform and Capacity Building Project (IRCBP) established the Decentralization Secretariat, the Local Government Finance Department (LGFD) and the Public Finance Reform Unit as units within the Ministries of Local Government and Rural Development and the MoFED with establishments and salaries determined by the project and significantly in excess of the regular civil service pay scales. Similarly, a large number of highly paid Local Technical Assistants (LTAs) were financed by the World Bank and other donors in the MoFED and, to a lesser extent in other ministries. (Note 21) More recently, to strengthen the health sector and implement the Free Health Care Initiative (FHCI) launched in 2010 the government bypassed the HRMO and the PSC and offered salaries outside of the civil service pay and grading structure to hire additional staff.

Other donor efforts have also exacerbated inter-agency rivalry by supporting to individual agencies (such as DfID support to the PSRU and EU and UNDP support to the HRMO), providing financial independence without providing complementary incentives to effectively engage with counterpart institutions. The World Bank was seen to be traditionally aligned to the MoFED making its engagement with the other MDAs more difficult.

\section{The Engagement Process}

\subsection{Overview}

\section{Background}

Public service reform has been a declared presidential priority since the mid-2000s. This was noted in the first Poverty Reduction Strategy Paper (PRSP I, 2005) and was re-emphasized in PRSP II (Agenda for Change, 2009). (Note 22) Prior to World Bank involvement, the GoSL began work on a comprehensive Civil Service Reform 
Program, but in the view of the political leadership this had not achieved very much. (Note 23) With the focus largely on form (e.g. management and functional reviews) rather than function, this is not surprising.

\section{World Bank engagement}

In the spring of 2011, the Finance Minister was faced with a challenging confluence of factors: a forecast of very high GDP growth fuelled largely by iron ore exports (originally estimated to be as high as $50 \%$ in 2012), mounting donor pressure for translating enhanced revenues that would accrue to the government into productive investment, and a civil service that was clearly not capable of managing the surge in revenues and the expected expansion of government activity. At the same time, in view of the imminent influx of resources, pressure to increase salaries across different segments of the civil service was mounting. (Note 24) The Minister of Finance could not easily accommodate these demands due to primarily fiscal constraints at least in the short term.

In November 2010, following a bilateral aid review which was undertaken across its portfolio after the change of government in the U.K., DfID had withdrawn its support to the PSRU, and to public service reform efforts in Sierra Leone more broadly,. The Finance Minister contacted the World Bank and it was agreed that that the Bank would explore the possibility of finding an appropriate way of supporting the government. The challenge for the Bank was complex: to provide relatively fungible resources to the government without assuming responsibility for an unsustainable wage bill and at the same time promote key reforms 1 .

The time frame was tight - the Bank only had eight months (Note 25) to prepare a project that would both help the GoSL meet its medium-term fiscal obligations and to set in motion a series of sustainable reforms to increase the productivity of the civil service. Relationships had to be built with the players and agencies with which the Bank had not engaged in the past.

Prior to formal initiation of the project, a scoping mission of the Public Sector Performance Global Expert Team in June 2011 concluded that any future efforts at civil service reform in Sierra Leone would be most effective using a results-based lending instrument coupled with intensive stakeholder engagement. The diagnostic conducted on that mission, suggested an approach with the following features: (i) Results focus. In view of political and capacity constraints and institutional fragmentation, as well as the record of low-performing public service reform projects in the past, a focus on tangible achievements along well identified reform paths was identified as a way forward. (ii) Quick disbursement. In order to be responsive to the needs of the GoSL, the project would best serve the client with an instrument that allowed it to begin disbursing as soon after effectiveness as possible. (iii) Quick wins. With the specter of elections in November 2012, there was an urgent need to show progress - both to the reform actors themselves and to the political leadership - prior to the (potential) change in the Administration. (iv) Ownership. The reform efforts should be restricted to areas where the government had already signaled a commitment.

In view of the institutional fragmentation and low levels of inter-agency trust it was extremely important for the Bank to play the role of "connector". In this fractured environment, the Bank would have to bring together the relevant actors to identify the problems that the project was to address, collectively arrive at solutions to promote local ownership and set the tone for a collaborative working relationship moving forward. To achieve this, the Bank had to first be accepted as a trusted partner.

A results-based instrument appeared to be the best suited and offered more flexibility than other instruments. A traditional input-based investment operation would not have focused attention on the end results, would not have engendered the inter-agency coordination that was needed, and would not have met the government's urgent need for additional fiscal space as all resources would be tied to inputs. While a DPF would have allowed for a focus on policy-level actions, and may have been the preferred instrument for government as it would provide fungible resources arguably with less effort, the various milestones and results along the reform paths identified by government and discussed with the Bank were not amenable to the "prior actions"/"triggers" framework of a DPF. More important, a DPF would not allow for the breaking down of the reform program into several small, manageable chunks spread across several years, the linking of specific results to discrete disbursements and would also not afford the opportunity for the intensive support and assistance that the reforms required.

The results-based financing instrument was chosen mainly to allow for several of the key elements of successful engagement recommended by the World Bank's new PSM approach and consistent with the PDIA approach. First, the results focus helps to create an authorizing environment in which "positive deviance" (Andrews et al 2012, pp. 13) and experimentation are possible, empowering agencies and individuals to find their own feasible paths for achieving agreed (proximate) targets. Second, the construction of the project along three parallel reform paths each 
with a series of discrete DLIs spread out over the life of the project and sequenced according to the degree of (technical and political) difficulty leaves open the space for experiential learning and feedback loops.

The preparation process for the Sierra Leone Pay and Performance Project had a difficult start. Counterparts in government (with the exception of the MoFED) were not familiar with the World Bank and even less so with the proposed instrument. (Note 26) For its part, the Bank lacked examples of success from similar projects. Initially, it was difficult to convince counterparts that the calls for "ownership" and a locally developed reform program were, indeed, not only genuine but necessary. During the September 2011 "identification" mission for the project, the Director of the PSRU told the Bank team: "You're wasting my time. Tell me what you need from us and get your consultants to write up the required documentation." The World Bank team was frustrated by the resistance to engage in meaningful dialogue with the government and to bring together the multiple agencies charged with different aspects of public service reform.

On hindsight, there were two related reasons for this kind of response: (i) the Bank had not worked with and the PSRU, HRMO or PSC and, for historical reasons, was seen as an ally of the MoFED which was not trusted by the others; (ii) these agencies, through their previous experience, were used to consultant- or donor agency-prepared projects and were initially unable to understand why they were being pushed to take responsibility for the technical aspects of project design.

From that point forward, the Bank team recognized that it would have make a considerable investment in "face-time" in order to build trust and complete the project in time. This involved an intense engagement, encompassing five two-week missions between September 2011 and April 2012. Each mission commenced with a kickoff meeting chaired by the Minister of Finance and included a series of technical meetings on each of the reform components with relevant government counterparts involving, at a minimum, four separate entities. Initially, meeting attendance was low and participation was limited. GoSL counterparts did not speak freely around one another or around Bank staff. With time and a repetition of the message that the reform paths and solutions would not be provided by the Bank team and would have to be identified by the GoSL team, counterparts gradually began to take on the tasks. Though initially the language and framework of results and reform paths was unfamiliar to the GoSL counterparts, through dialogue with the Bank team, key stakeholders grasped the logic of the approach and began to see the potential benefits of the approach. And though the GoSL used a consultant whom it engaged to liaise with the Bank on technical matters, representatives of different agencies began to see that the project represented an opportunity to push reforms that would make their institutions more capable, more efficient, and better respected by colleagues in government and in the donor community. They resistance gradually reduce and involvement increased. Gradually trust built, with the Bank team and across agencies. Frank conversations were held between the Bank team and GoSL counterparts on constraints facing the project, including political challenges and institutional capacity constraints.

The Bank team knew that the GoSL counterparts had begun to coalesce around the project during the preparation mission in December 2011. The heads of the HRMO, PSRU and PSC - previously difficult to get in a room together - requested a joint meeting with the Minister of Finance. As the Bank team observed, they expressed the need for the Minister to join them in the reform effort in both a technical and political capacity. On a technical level, they needed him to ensure that the funds needed for implementation would be provided. On a political level, they needed him to champion the project in Cabinet. (Note 27) Impressed by the newfound cohesion of his colleagues, the Minister assented. This core group of the PSRU, HRMO, PSC and MoFED was the nucleus of a group subsequently identified as the "Leadership Team" and formalized by executive decree.

Six months after the identification mission, the GoSL team which included the heads of the PSRU, the HRMO, the PSC and a delegation from the MoFED led by the Minister of Finance was in Washington for the negotiations for the project. (Note 28) The negotiations revealed that the GoSL team had undergone a 180-degree change - from a disparate group of actors with limited interest in the project, to a cohesive team with significantly greater ownership of the reform effort and belief in the possibility of success. The Director of the PSRU succinctly summarized this transformation by noting: "This project - our project - has taught all of us in Government to work together."

The momentum continued and was visible during the first implementation support mission in September 2012. At the final technical meeting of the mission, the Director of the PSRU, commenting on joint efforts to meet early DLIs of the project remarked: "This collaboration is unprecedented." Furthermore, in reference to the new mode of engagement with the Bank and with colleagues in government, he stated that the project "is not like other projects that come from above. Here, we sit together." 


\section{Choice of Milestones, Results and DLIs}

The Bank team and government jointly agreed to a total of 15 DLIs for the three sub-components. For each of the sub-components, these progress over the project life from relatively simple to more challenging and from de jure measures to de facto changes in practices. For example, for the Recruitment and Staffing sub-component the first DLI is the drafting and approval of "open, competitive and merit-based Recruitment Procedures" (indicator 2.1 in Annex 2). Subsequent DLIs involve actual recruitment of personnel to fill priority vacancies. The last DLI requires that at least $90 \%$ of the recruitments have been made to fill priority vacancies (indicator 2.6 in Annex 2). The first indicator is essentially a "stroke of the pen" measure, completed by a limited group of civil servants without any implication of sustained behavioral change, with potentially limited impact on the broader civil service on its own. The subsequent DLIs, by contrast, measure a change in performance involving a much wider group of individuals, directly involving all those who participate in recruitment processes. While the DLIs could have been structured in such a way as to place more weight on a limited set of advanced-stage indicators, thus leaving more flexibility at the beginning of the reform process, including simpler early-stage indicators was perceived to have two main advantages. First, it clarified how to initiate the daunting reform process, removing potential uncertainty regarding which actors were to make the first steps, in what technical area, and with what objective. Second, it facilitated several early wins to keep interest and confidence alive and overcome potential reform fatigue - a key risk highlighted by government counterparts. This is particularly important for building the confidence of the MoFED in the process and in this way increasing the leverage of the other agencies as the reforms progress. While not offering the kind of mid-course flexibility (or ex-post flexibility, in reference to the initiation of implementation) advised by PDIA, this approach did allow for ex-ante agnosticism about what might work and flexibility in design. Figure 2 displays the contrast with operating space for development organizations as previously presented (Figure 1).

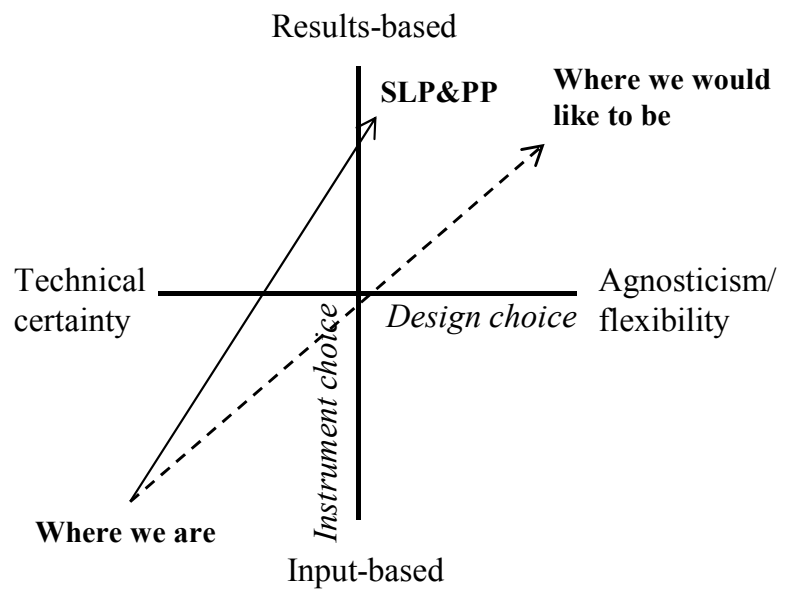

Figure 2. Operating space for development organizations: the SLP\&PP (Note 29)

\section{Anecdotal Evidence: How Did a Problem-Solving Focus and Results-Based Lending Help Build Trust and Enhance Coordination?}

It became clear fairly early on that several agencies would need to work together to achieve the key milestones and results (identified by the DLIs) along the three reform paths. This was foreseen by the Secretary to the President at a very early stage, who, upon learning of the results-based approach, noted that it would "force joined-up working". From the World Bank team's perspective, the engagement rested on an insistence that the key stakeholders would have to collectively devise their own solutions, that these would not be provided or dictated by the World Bankand identify DLIs central to their reform goals. Given this dynamic, the implementing agencies were forced to place the mutual dependency inherent in the interconnected sets of activities - and thus the consultative process for agreeing on these targets and how they were to be achieved - front and center.

The following examples illustrate how the Bank team used its role as "connector" as well as the incentives offered by the results-based instrument to improve inter-agency coordination, build trust and achieve concreteresults. 


\subsection{Strengthening Budget Dialogue between MDAs and the Ministry of Finance}

As noted, the relationship between the three core agencies responsible for the Program (PSRU, PSC and HRMO) with the MoFED had traditionally been characterized by mutual distrust. These agencies had often complained that their budget requests were largely ignored by the MoFED, ad hoc cuts applied and a fraction of the requested amounts allocated. They also noted that their allocations would often arrive late or incomplete impeding their ability to implement their programs. The MoFED argued that the budget requests were unreasonable non-strategic "laundry lists", leaving it with no option but to reject large portions of the requests by making ad hoc cuts. The PSR implementing agencies felt disadvantaged politically, as they lacked representation in cabinet and had limited access to the President as a group.

The results-based instrument provided incentives for the Ministry of Finance and the MDAs to improve their dialogue. The disbursements ("rewards") for the achievement of DLIs would accrue to the consolidated fund as fungible resources that the MoFED could allocate as needed. However, for the project to disburse, the implementing agencies needed to achieve the DLIs for which they would need to be adequately resourced. (Note 30) Without resources to carry out the required activities, the DLI would not be achieved and the consolidated fund/MoFED would not receive the associated disbursement. In each mission, discussions with similar dynamics were held around all the DLIs across the three technical areas of the project (pay reform, recruitment and staffing, and performance management) - 15 DLIs in total worth $\$ 15$ million in disbursements were identified. The DLIs were "priced" equally so as to guarantee predictable flows into the consolidated fund subject to their achievement. Aware of the dynamic of mutual dependency, the Minister of Finance at a meeting during the first implementation support mission offered that the PSRU, HRMO and PSC submit a joint proposal outlining the resources necessary to reach the DLIs, which, upon review of the MoFED, would be "ring-fenced" - effectively guaranteeing the necessary flow of financing to carry out the reform activities. This agreement gave the PSRU, HRMO and PSC new leverage in budget negotiations by giving the MoFED a concrete interest in their program of activities linked to the project. (Note 31)

\subsection{Bringing Together the Ministry of Finance and the HRMO to Discuss Recruitment Targets}

Prior to the initiation of project preparation, MoFED and HRMO (whose offices are across the street from one another) had typically not met to discuss the fiscal space available for new recruitment. Traditionally, during the manpower hearing process (part of the budget calendar) the HRMO would receive long, un-prioritized lists of positions to be filled from the MDAs. The HRMO would, in turn, pass on these requests "as-is" to MoFED. On the largely legitimate grounds that these requests were unaffordable and unrealistic the MoFED would generally ignore them. (Note 32) As a result, recruitment during the course of the year was carried out on an ad hoc basis. Thus, recruitment was non-strategic and, at times, off-budget. (Note 33) It was clear that this was not a technically difficult issue and that significant improvements could be achieved with better communications and trust. The World Bank team facilitated a series of meetings between the HRMO and the MoFED to improve communications on this issue. The subtext of the meetings was that the Recruitment and Staffing component of the project, led by the PSC, envisioned a series of DLIs that measured the percentage of "priority appointments" made according to a new set of recruitment procedures. However, the number of "priority appointments" depended entirely on an agreement reached between the HRMO and the MoFED. The starting point for the discussions was the 1084 new positions requested for 2012 which the MoFED had not taken seriously and ignored. Through the dialogue facilitated by the Bank, the MoFED confirmed that resources were available for about 350 positions in 2012 - information that it had not shared before. Based on this envelope, the HRMO created a prioritized list in consultation with the MDAs. The prioritization criteria was the requirement of technical and professional positions (grades 6 and above) in the eight priority ministries identified in the government's Agenda for Change. Following this discussion, the first year DLI was at $60 \%$ of the agreed number (Note 34), with the agreed recruitment target increasing to $80 \%$ and $90 \%$ in years 2 and 3.

\subsection{Bringing Together HRMO, PSC and MoFED to Reach Closure on the Mainstreaming of LTAs}

The issue of "mainstreaming" Local Technical Assistants (LTAs) is a challenge that spanned several World Bank projects. LTAs, originally hired through donor-financed projects to temporarily supplement capacity in key government positions in several MDAs have, in fact, increased in numbers over the years and have become a prevalent but uncomfortable feature of the civil service landscape. They occupy line positions but have generally been recruited outside of formal systems and are remunerated at levels much higher than regular civil servants (increasingly out of the consolidated fund). Though most donor projects for which they were hired had closed, the LTAs were retained by government - at their elevated salaries - without ever having to compete for their positions. 
This has exacerbated tensions with the regular public servants and has served to erode the esprit de corps. It has long been recognized that the issue has to be addressed but almost no progress has been made.

Recognizing the inequity and demoralizing effect of this dual system, the World Bank and government agreed that the institution of LTAs had to be satisfactorily integrated into the civil service ("mainstreamed") starting with the MOFED, home to the largest group of LTAs. In 2009, the negotiations for the Integrated Public Financial Management Project (IPFMRP), which had attempted to support the mainstreaming of LTAs, were delayed over this issue. The problem was that the MoFED and the implementing agencies responsible for recruitment and human resource management could not find common ground. At the time, the issue was postponed through a disbursement condition for $\$ 3$ million which would only be disbursed subject to the completion of a set of "mainstreaming" steps. No progress had been made on meeting this disbursement condition of the IPFMRP since the project had become effective in December 2009. (Note 35)

The challenges came from several directions. First, the MoFED perceived a risk of losing much needed technical capacity currently filled by LTAs. Second, there was resistance from the LTAs who too perceived a threat: any mainstreaming plan would require positions currently occupied by LTAs to be filled by an open, competitive recruitment process led by the PSC. This put some of the LTAs within MoFED in charge of implementing a plan that could potentially endanger their own employment. Additionally, the agencies responsible for PSR and representing the general civil service saw mainstreaming as a way of legitimizing the higher salaries and status of the LTAs rather than as a program of rationalization and integration.

During the course of the preparation missions for the P\&PP, the Bank team reopened the dialogue. As a first step the team was able to get all of the key actors - representatives of MoFED, HRMO, PSC and external consultants - to openly discuss the issue and consider including a DLI on "LTA mainstreaming" in the project. The negotiations on this DLI spanned several missions and were complex, especially since some of the representatives from MoFED were LTAs themselves. In the end, the relevant actors agreed on a five-step LTA mainstreaming process captured in one DLI that satisfied all the parties. To be consistent with recruitment regulations, it required posts currently occupied by LTAs to be filled through competitive processes in which incumbents could participate. To satisfy the LTAs speaking for MoFED, it allowed for salary levels to stay at their current levels through the option of a "scarcity/market premium" to bridge any gap between the civil service pay structure and current remuneration rates (contingent upon the results of a remuneration survey) and/or by "grandfathering" remuneration levels for LTAs who would retain their positions. At the time of writing some forward movement has been made. It remains to be seen how much progress will be made but, at least, there is some agreement on the way forward.

\section{Conclusion}

This paper has described the role that intensive, client-led engagement and the use of a results-based lending instrument played in the preparation process for the Sierra Leone Pay and Performance Project. Only time will tell if the early positive results achieved in the preparation process and in the early implementation phase will translate into real and sustainable gains as project implementation continues. But it does appear that there will be some progress where there had been none in the past, with respect to government ownership and understanding of reforms, inter-agency cohesion and World Bank-GoSL relations. One advantage of the approach used, however, is that measuring the results will be straightforward due to the use of the results-based instrument. Simply put, if the project disburses fully, the project is a success, and if not, it will still be a partial success. Disbursement will not be the sole metric for the effectiveness of the project design and preparation approach techniques described in this paper, as other factors such as changes in the political and administrative leadership or exogenous economic shocks could greatly impact its success.

Though the experience from this project in Sierra Leone provides encouraging empirical evidence in support of an incremental problem-solving approach, complemented with a results-based financing instrument for complex public sector reform challenges in a difficult environment, it is important to note potential limitations to a more universal validity of these findings. There are several elements that played key roles in the preparation process that may be difficult to replicate in future operations. First, key team members of the Bank's team had worked in Sierra Leone for several years prior to the initiation of the engagement on the P\&PP. These previous projects allowed them to develop an intimate understanding of the political environment and to establish relationships of trust with key individuals in government.

Second, the importance of the individuals leading the GoSL institutions and interpersonal dynamics among them cannot be discounted - the dialogue-heavy preparation process could have taken a completely different course should any one of the key counterparts behaved differently - and are certainly unique to this particular case. 
Finally, World Bank management was especially supportive of the "experimental" approach taken to preparation and the risks entailed, despite the Bank's general aversion to risk. The Bank's "connector" role was and continues to be extremely critical. The experience shows that inter-agency coordination is far from institutionalized and falters between Bank missions. In this sense, the project is more a platform for dialogue than a set of activities amenable to traditional "supervision" or "implementation support". The cost of this kind of engagement is high. Thus, the Bank is faced with a choice: though the total project value of the financing ( $\$ 17$ million) is relatively small, the World Bank has had to invest more in design and implementation support than in traditional projects. More than the typical two short supervision missions per year, resources would need to be made available for significant staff time, more frequent missions and specialized technical assistance to fully realize the project's potential and help the government achieve urgently-needed institutional transformation. Indeed, if the incentives are in favor of high value low cost projects (such as DPFs), interventions of this kind will be hard to sell internally. On the other hand, the returns in terms of sustainable institutional development can be high.

\section{Update}

The government counterparts leading and implementing this Project have made substantial and meaningful progress towards introducing a culture of performance to the Sierra Leonean civil service. Year 0 and Year 1 DLIs have been accomplished, Year 2 DLIs largely achieved and Year 3 DLIs are underway. Given that Year 3 DLIs are focused more on institutionalizing a culture of performance, and targets aim to address more systemic issues, achievement of these indicators was anticipated to be more challenging - and this has, indeed, turned out to be the case. Progress on these DLIs has also slowed significantly in recent months due to the severe outbreak of the Ebola virus and the government declared State of Emergency that has hindered many activities by Implementing Agencies. The Project will be extended by one year to take account of the tragic situation arising from the Ebola outbreak and to allow work to continue once the environment stabilizes.

While significant challenges were encountered in early stages of the project related to flow of funds from the World Bank to the government and - using existing country systems - onward to individual Implementing Agencies, much learning has taken place on this process and it more recently appears to be smoother than was the case initially in 2013. Early implementation has been supported by the World Bank's Leadership for Results Program, which employs periodic leadership fora and Rapid Results coaching and training to strengthen local teams' ability to achieve program milestones (Winning and Panzardi 2015).

Implementation support provided by the World Bank throughout the lifetime of the project has contributed to greater focus and collaboration across agencies, helping to foster a sense of joint accountability amongst actors to achieve results. The Director of Strategy and Planning in the Human Resource Management Office (HRMO) attests that "this program has brought us all together under one umbrella - it's a very big step we've taken...We must emphasize lessons learned from the process in the past year and more... The point is we had to bring everyone on board and everyone has now been brought on... I'm very hopeful and happy for the level of collaboration we have attained".

\section{Acknowledgements}

The authors are also indebted to Nick Manning, Marco Larizza, Jurgen Blum and Kevin Brown for their valuable feedback and suggestions. The authors are also very grateful to Julius Sandy, Val Collier, Ernest Surrur and other colleagues in the Government of Sierra Leone for their inputs. The findings, interpretations, and conclusions expressed in this paper are entirely those of the authors. They do not necessarily represent the view of the World Bank Group, its Executive Directors, or the countries they represent.

\section{References}

Andrews, M. (2008). Creating Space for Effective Political Engagement in Development. RWP 08-015, Harvard University.

Andrews, M., Pritchett, L., \& Woolcock, M. (2012). Escaping Capability Traps through Problem-Driven Iterative Adaptation (PDIA). Center for Global Development, Working Paper 299.

Barber, M. (2008). Instruction to Deliver: Tony Blair, the Public Services and the Challenge of Delivery. London, Politicos.

Barber, M., Kihn, P., \& Moffit, A. (2011a). Deliverology: From Idea to Implementation. Washington DC, McKinsey and Co. 
Barber, M., Moffit, A., \& Kihn, P. (2011b). Deliverology 101: A Field Guide for Educational Leaders. Thousand Oaks, Sage.

Blum, J., Manning, N., \& Srivastava, V. (2012). Public Sector Management Reform: Toward a Problem-Solving Approach. Washington DC, World Bank.

Booth, D. (2009). Elites, Governance and the Public Interest in Africa: Working with the Grain?. Africa Power and Politics, Working Paper No. 9.

Booth, D. (2012). Development as a Collective Action Problem: Addressing the Real Challenges of African Governance. Overseas Development Institute, 2012.

Evans, A. (2008). Civil Service and Administrative Reform: Thematic Paper. Background Paper to Public Sector Reform: What Works and Why? An IEG Evaluation of World Bank Support, Washington D.C.: World Bank.

Government of Sierra Leone. (2008). An Agenda for Change: Second Poverty Reduction Strategy 2008-2012. Freetown.

Government of Sierra Leone. (2012). Improving Productivity through Management and Pay Reforms. Freetown.

Kelsall, T. (2008). Going with the Grain in African Development?. Development Policy Review, 26(6), 627-55.

Kotter, J. (1995, March-April). Leading Change: Why Transformation Efforts Fail. Harvard Business Review, Cambridge: Harvard University.

Manning, N., \& Watkins, J. (2013). Targeting results, diagnosing the means: innovative approaches for improving public sector delivery. Washington DC, World Bank, unpublished draft.

Polidano, C. (2001). Why Civil Service Reforms Fail. IDPM Public Policy and Management Working Paper, No. 16, University of Manchester.

Schein, E. (1996). Kurt Lewin's Change Theory in the Field and in the Classroom: Notes Toward a Model of Managed Learning. Systems Practice, 9(1), 27-47.

Srivastava, V., \& Marco, L. (2013). Working with the Grain for Reforming the Public Service: A Live Example from Sierra Leone. International Review of Administrative Sciences, special edition: The World Bank's approach to public sector management, 79(3).

Winning, K., \& Panzardi, R. (2015). Leading, Learning and Adapting Toward Development Results: An Example from Civil Service Reform in Sierra Leone. Mimeo.

World Bank. (2011). A New Instrument to Advance Development Effectiveness: Program-for-Results Financing. Operations Policy and Country Services.

World Bank. (2012a). The World Bank's approach to Public Sector Management 2011-2012: Better Results from Public Sector Institutions. Washington, D.C.: World Bank.

World Bank. (2012b). Sierra Leone Pay \& Performance Project - Project Appraisal Document. Report 67447-SL, May 7, 2012. Washington, D.C.: World Bank.

\section{Notes}

Note 1. A recent paper (Manning and Watkins 2013) includes "Deliverology" (Barber et al., 2011b; Barber, 2008; Barber et al., 2011a) - with its genesis in the experience of the Prime Minister's Delivery Unit in the United Kingdom - as a third approach within this group with a focus on pragmatic context-specific solutions. While the general strategy behind "Deliverology" is strikingly similar to the PSM Approach and to PDIA, the specific tactic of delivery units is pre-determined.

Note 2. See, among others: "A New Instrument to Advance Development Effectiveness: Program-for-Results Financing," Operations Policy and Country Services, World Bank, 2011; "Results-Based Lending Approaches in Social Protection and Labor: World Bank Experiences," Social Protection and Labor Policy Note, World Bank, 2011; "Results Based Financing Mechanisms: Experience from Output Based Aid," CIF Partnership Forum, World Bank, 2011.

Note 3. See, among others: Grindle, M. (2004) "Good Enough Governance: Poverty Reduction and Reform in Developing Countries," Governance, Vol. 17, No. 4.

Note 4. The PDO for the project is to "Improve competitiveness in pay, performance management and accountability 
of, and increase staffing of middle and senior staff in, the civil service in Sierra Leone". See the Sierra Leone Pay and Performance Project PAD, World Bank Report 67447-SL, 2012.

Note 5. This is the first World Bank/IDA intervention in support of Civil Service Reforms in Sierra Leone. The World Bank/IDA had hitherto focused on Public Financial Management and Decentralization with while the European Union (EU) and the UK Department for International Development (DfID) had been taking the lead on Public Service Reforms since the end of the conflict. In 2010 DfID withdrew its support to the sector following the change of government in the UK and bilateral aid reviews that followed.

Note 6. The story of Sierra Leone's experience with "Deliverology" is told in: Scharff, M. (2012) Delivering on a Presidential Agenda: Sierra Leone's Strategy and Policy Unit, 2010 - 2011, Princeton, Princeton University.

Note 7. There is some early positive evidence of progress in implementation: since declaring project effectiveness in October 2012. Three out of 15 Disbursement-Linked Indicators (DLIs) have been fully achieved and significant advances have been made on three additional DLIs.

Note 8. A "companion" paper (Srivastava and Larizza 2012) reviews the same case to show how the reform solutions that emerged from the use of a results-based approach were more likely to "work with the grain" of political incentives and, thus, have a greater chance of success.

Note 9. Based on a personal conversation with Nick Manning and on a presentation made by him to the OECD-DAC Network on Governance in Paris on April 222013.

Note 10. Previously this was called "Investment Lending".

Note 11. Previously this was called "Development Policy Lending".

Note 12. A recent review of 178 World Bank DPFs (active during 2010-2012) showed that less than 10\% of the prior actions meet the behavioral test.

Note 13. According to the Program for Results Policy Paper (2011), "These programs, comprising expenditures and activities, can be ongoing or new, sectoral or sub-sectoral, and national or sub-national programs, as well as community development programs" (pp. iv).

Note 14. This approach is consistent with the principles of the Paris Declaration on Aid Effectiveness and the subsequent fora in Accra and Busan. See: http://www.oecd.org/development/aideffectiveness/34428351.pdf

Note 15. These arguments are presented in greater detail in the Project Appraisal Document (PAD) for the Sierra Leone Pay and Performance Project, World Bank Report No: 67447-SL, 2012.

Note 16. According to a recent Public Expenditure Review (PER) (World Bank 2010), the comparable figure was 7\% in 2008. The "civil service" in Sierra Leone includes health workers but not teachers who are included in the "public service" count but not in the "civil service".

Note 17. Figures for Gambia are from the payroll for 2007; figures for Sudan are from Background Paper for 'Sudan: Joint Assessment Mission', unpublished mimeo, World Bank, 2004.

Note 18. "Rapid Assessment of Dynamics of Public Sector Reform in Sierra Leone," report prepared by Sidi Koroma, Positive Change Human Resource Consultancy Services, Unpublished, Sierra Leone, May 2011.

Note 19. Ibid.

Note 20. See previous footnote.

Note 21. As agreed jointly by the HRMO, PSC, MoFED and PSRU (2012), LTAs are defined as "all non-politically appointed Government of Sierra Leone employees currently engaged in the Civil Service whose recruitment and appointment was not effected by the Public Service Commission or the Human Resources Management Office".

Note 22. "It is our conviction that no economic transformation is possible without a transparent, accountable and effective public sector dedicated to providing supportive policies and actions. In this respect it is our intention to reform the public sector, support the private sector, modernize the financial sector, and robust action on corruption". President Ernest Koroma, Opening Statement, Agenda for Change.

Note 23. In 2010 the PSRU was asked to appear before a pre-cabinet meeting to explain what it had been doing. While PSRU had focused on several initiatives (such as Management and Functional Reviews) these had not borne the desired results.

Note 24. The Free Health Care Initiative also led to an increase in the salaries of health workers and created 
pressures for across the board salary increases. Starting with ad hoc increases for health workers in 2010 and for teachers and the rest of the civil service in 2011, the wage bill in 2011 is estimated to be $27 \%$ higher than in 2010 ; the cumulative increase by the end of 2012 was expected to be almost $50 \%$.

Note 25. Due to an internal Bank requirement, the task team was required to present the project for approval by the Bank's Board of Executive Directors prior to the close of the fiscal year in June, which in practice meant completing preparation activities by May.

Note 26. Prior to this, the Bank had not engaged on civil service reforms and its support had been limited to PFM and decentralization.

Note 27. Under the Constitution, the President is technically the Minister for Public Service. However, the President de facto does not fill this role as a member of cabinet, thus leaving the Minister of Finance as the cabinet official with the closest relationship with issues pertinent to civil service reform. Prior to this project, the Finance Minister's engagement in civil service reform had been limited largely to monitoring and control of the wage bill.

Note 28. The negotiations were scheduled during the Spring Meetings to facilitate broader GoSL participation, in particular by the MoFED.

Note 29. See footnote 8.

Note 30. For example, to meet the DLI requiring that a group of pilot ministries carry out one round cycle of annual performance evaluations for mid-level civil servants, the HRMO will require financing for several inputs and activities, including hiring and training performance management staff as well as conducting training workshops for line managers on the new performance management system.

Note 31. It would be fair to say that the dialogue between the implementing agencies and the MoFED has improved but there is still a long way to go.

Note 32. The lists would often be quite large - the most recent list (2012) requested 1084 new hires, equivalent to a $13 \%$ increase in the size of the civil service in one year.

Note 33. For instance the Ministry of Mines recruited Inspectors using retained revenues.

Note 34 . The target was agreed in the middle of the fiscal year 2012 by which time only 24 recruitments had been completed.

Note 35. The relevant component of the IPFMRP has since been canceled. 
Annex 1. SLP\&PP - Project Components and Implementation Arrangements

The project provides US \$ 15.0 towards a US \$ 200 million GoSL reform program reform. Disbursements of US $\$ 1.0$ million are made for the achievement of each DLI (see Annex 2). The GoSL program has the following elements.

\section{Component 1: Support to the GoSL's Reform Program}

\section{Sub-component 1.1: Pay reform}

The objectives of this sub-component are: (a) to attract and retain key professional and managerial staff; and (b) to motivate all civil servants to perform their jobs to an acceptable standard.

Equitable pay and more competitive pay will be introduced through the development of a new pay structure for the civil service. In parallel a labor market survey will be conducted to provide a basis for establishing the salary ranges for each grade and, where necessary, the size of any market supplements that need to be paid for specific jobs. In addition, the survey will take a long-term perspective by examining the future demand for skills in the economy which are needed by the civil service. The information from the job evaluation and the labor market survey will be brought together to develop a new salary structure.

\section{Sub-component 1.2: Recruitment and staffing}

The objective of this sub-component is to create a capable civil service of the right size and job composition to deliver its core functions assigned by government.

At the start of the Project, PSC in collaboration with the HRMO will develop a revised open, competitive and competency based recruitment procedure. The procedure will be approved by the CSSC. The PSC will also develop a recruitment strategy which sets out the priorities for recruitment to the managerial, professional and technical grades (which jobs, which sectors) and explicit criteria for their determination. Processes will be established to identify and develop existing civil servants who have the potential to perform jobs of higher responsibility in future. The design of a high potential development scheme for junior and mid-level professionals will be a key milestone in the second year of the Project. But since there can be no guarantees of progression, a new promotions procedure will be developed to ensure that all promotions to management positions are based on merit following an open and competitive process. The new procedure will be managed and overseen by the PSC.

\section{Sub-component 1.3: Performance management and accountability}

The objectives of the performance management component are to: (a) improve the performance and productivity of ministries and individual civil servants; (b) increase citizens' trust in government; (c) strengthen the accountability of ministries to the executive and citizens.

Performance contracting. The HRMO will initially develop comprehensive guidelines for performance contract management which will cover civil service managers. The guidelines will assist ministries in formulating annual output-based performance targets and work plans for each department, establishing an information system to generate regular performance reports, carrying out quarterly performance reviews and taking corrective action to bring actual performance closer to targeted performance. External assessments of the performance of civil service managers will be carried out by HRMO's Performance Management Unit for which it will be appropriately staffed and trained.

Individual performance appraisal. The new individual performance appraisal process will be implemented in phases. The system will first be tested and refined in eight pilot ministries before it is rolled out to all 22 ministries. Human 
Resource and Performance Management (HRPM) units in all ministries will be fully staffed and trained to facilitate the introduction of the new process in their respective ministries. The HRMO will complete the design of the new process, including the necessary report forms, the guidelines and the data base for collecting information on the functioning of the process in individual ministries. It will then be responsible for communicating the new process to individual ministries whose senior managers in turn will brief their managers and staff, supported by their HRPM units. Managers will be trained to agree individual targets and conduct effective appraisal discussions.

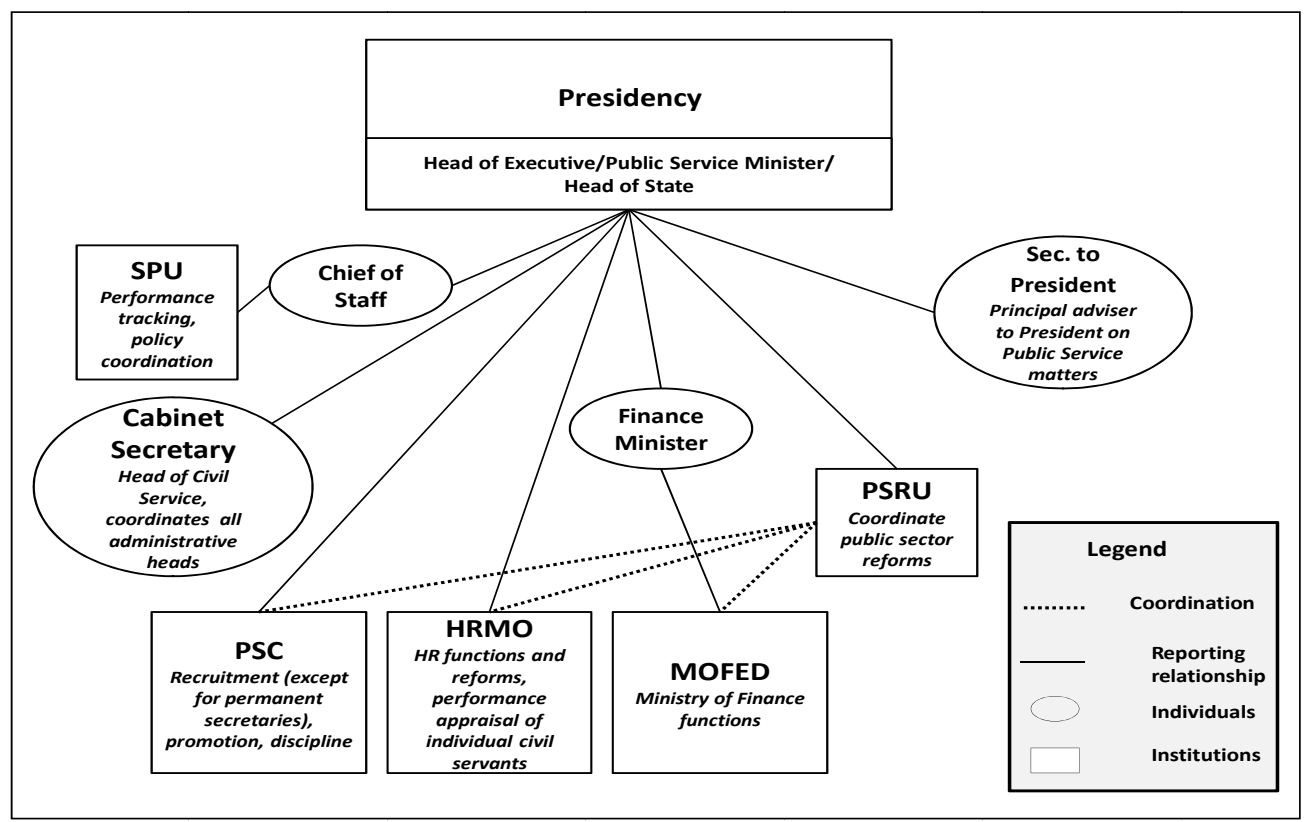

Figure 1. Actors and institutions associated with PSR in Sierra Leone

Source: World Bank, 2012b

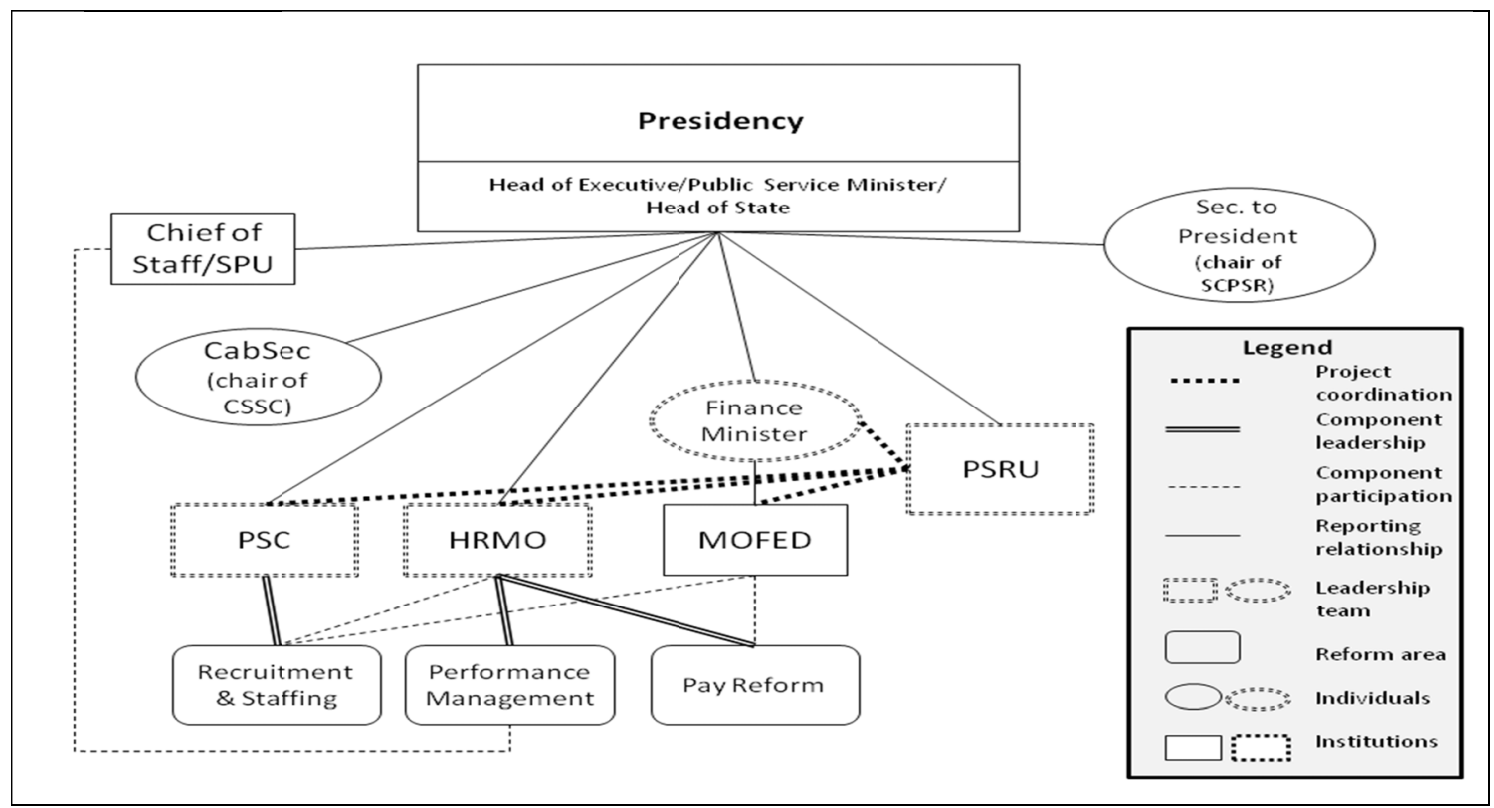

Figure 2. P\&PP implementing agencies

Source: World Bank, 2012b 
Annex 2. Disbursement Linked Indicators

\begin{tabular}{|c|c|c|c|c|}
\hline $\begin{array}{l}\text { DISBURSEMENT } \\
\text { LINKED } \\
\text { INDICATOR }\end{array}$ & $\begin{array}{c}\text { ACTIONS TO BE COMPLETED } \\
\text { FOR DISBURSEMENTS IN YEAR } \\
0 \\
\text { (THROUGH JUNE 30, 2012) }\end{array}$ & $\begin{array}{l}\text { ACTIONS TO BE COMPLETED } \\
\text { FOR DISBURSEMENTS IN YEAR } \\
1 \\
\text { (JULY 1, 2012 THROUGH } \\
\text { DECEMBER 31, 2012) }\end{array}$ & $\begin{array}{l}\text { ACTIONS TO BE COMPLETED FOR } \\
\text { DISBURSEMENTS IN YEAR } 2 \\
\text { (CALENDAR YEAR } 2013\end{array}$ & $\begin{array}{c}\text { ACTIONS TO BE COMPLETED } \\
\text { FOR DISBURSEMENTS IN } \\
\text { YEAR } 3 \\
\text { (CALENDAR 2014) }\end{array}$ \\
\hline (1) Pay reform & $\begin{array}{l}\text { (1.1) HRMO has conducted and } \\
\text { completed a remuneration } \\
\text { survey. }\end{array}$ & & $\begin{array}{l}\text { (1.2) All Civil Service jobs have } \\
\text { been evaluated in accordance with a } \\
\text { Job Evaluation Scheme and assigned } \\
\text { to a Grading Structure approved by } \\
\text { the CSSC. } \\
\text { (1.3) } 100 \% \text { of Civil Servants in } \\
\text { Grade } 6 \text { and above are paid in } \\
\text { accordance with the approved Pay } \\
\text { Structure. }\end{array}$ & \\
\hline $\begin{array}{l}\text { (2) Recruitment } \\
\text { and staffing }\end{array}$ & $\begin{array}{l}\text { (2.1) The appropriate open, } \\
\text { competitive and merit-based } \\
\text { Recruitment Procedures have } \\
\text { been designed by PSC in } \\
\text { collaboration with HRMO and } \\
\text { approved by CSSC.(2.2) Seven } \\
\text { staff have been recruited to } \\
\text { PSC and trained to manage } \\
\text { recruitments and selection. }\end{array}$ & $\begin{array}{l}\text { (2.3) At least } 60 \% \text { of Priority } \\
\text { Vacancies have been filled in } \\
\text { accordance with the Annual } \\
\text { Recruitment Plans and the } \\
\text { approved } \\
\text { Procedures. Recruitment }\end{array}$ & $\begin{array}{l}\text { (2.4) At least } 80 \% \text { of Priority } \\
\text { Vacancies have been filled in } \\
\text { accordance with the Annual } \\
\text { Recruitment Plans and the approved } \\
\text { Recruitment Procedures. } \\
\text { (2.5) LTAs have been integrated in } \\
\text { accordance with an approved } \\
\text { Mainstreaming Policy and Action } \\
\text { Plan. }\end{array}$ & $\begin{array}{l}\text { (2.6) At least } 90 \% \text { of Priority } \\
\text { Vacancies have been filled in } \\
\text { accordance with the approved } \\
\text { Recruitment Plans and the } \\
\text { approved } \\
\text { Procedures. Recruitment }\end{array}$ \\
\hline $\begin{array}{l}\text { (3) Performance } \\
\text { management }\end{array}$ & & $\begin{array}{l}\text { (3.1) Appropriate guidelines for } \\
\text { Performance Contract } \\
\text { management for Civil Servants } \\
\text { in Grade } 11 \text { and above in all } \\
\text { Ministries have been prepared } \\
\text { by HRMO and approved by } \\
\text { CSSC. }\end{array}$ & $\begin{array}{l}\text { (3.2) All Pilot Ministries have } \\
\text { completed one annual cycle of the } \\
\text { Performance Appraisal Process for } \\
\text { Civil Servants in Grades } 7 \text { to } 10 \text {. }\end{array}$ & $\begin{array}{l}\text { (3.3) At least } 80 \% \text { of the } \\
\text { annual Performance Appraisal } \\
\text { Reports for calendar year } 2014 \\
\text { for Civil Servants in Grade } 7 \\
\text { to } 10 \text { in Pilot Ministries are of } \\
\text { appropriate quality. } \\
\text { (3.4) At least } 80 \% \text { of the } \\
\text { annual Performance Reports } \\
\text { for calendar year } 2014 \text { for } \\
\text { Civil Servants in Grade } 11 \text { and } \\
\text { above on Performance } \\
\text { Contracts in Pilot Ministries } \\
\text { are of appropriate quality. } \\
\text { (3.5) All Ministries' } \\
\text { performances against } \\
\text { Performance Targets have been } \\
\text { evaluated jointly by the } \\
\text { Recipient and relevant } \\
\text { non-state actors. } \\
\text { (3.6) Publication of: (i) all } \\
\text { Ministries' Performance } \\
\text { Targets; and (ii) achievements } \\
\text { against Performance Targets. }\end{array}$ \\
\hline
\end{tabular}

